\title{
Hypoplastic left heart syndrome and the allure of a valved conduit
}

\author{
Harold M. Burkhart, MD, ${ }^{\mathrm{a}}$ Arshid Mir, MD, ${ }^{\mathrm{b}}$ and Jess L. Thompson, $\mathrm{MD}^{\mathrm{a}}$
}

\footnotetext{
From the ${ }^{\mathrm{a} D i v i s i o n}$ of Cardiovascular and Thoracic Surgery, and ${ }^{\mathrm{b}}$ Section of Pediatric Cardiology, University of Oklahoma Health Sciences Center, Oklahoma City, Okla.

Disclosures: Authors have nothing to disclose with regard to commercial support.

Received for publication Dec 1, 2017; accepted for publication Dec 18, 2017; available ahead of print Jan 19, 2018.

Address for reprints: Harold M. Burkhart, MD, Division of Cardiovascular and Thoracic Surgery, University of Oklahoma Health Sciences Center, College of Medicine Bldg, 800 Stanton L. Young Blvd, Suite 9000, Oklahoma City, OK 73104 (E-mail: Harold-burkhart@ouhsc.edu).

J Thorac Cardiovasc Surg 2018;155:1745-6

$0022-5223 / \$ 36.00$

Copyright (c) 2017 by The American Association for Thoracic Surgery

https://doi.org/10.1016/j.jtcvs.2017.12.074
}

There are known knowns. These are things we know that we know. There are known unknowns. That is to say, there are things that we know we don't know. But there are also unknown unknowns. There are things we don't know we don't know.

$$
\text { -Donald Rumsfeld }
$$

The surgical treatment of hypoplastic left heart syndrome (HLHS) has undergone numerous modifications over the past few decades in hopes of improving surgical outcomes and survival. Modifications in the Norwood operation continue to grow, focusing on arch reconstruction, hybrid approaches, as well as cardiopulmonary bypass techniques. Sources of pulmonary blood flow used in the Norwood operation have been a debated topic, with increasing support for the right ventricle to pulmonary artery (RV-PA) conduit over the past several years. ${ }^{1-3}$ The advantages of the RV-PA conduit include less diastolic runoff with a lower Qp:Qs, which can contribute to postoperative stability. Concerns exist regarding the effects of conduit regurgitation and the ventriculotomy on cardiac function and tricuspid valve regurgitation. Theoretically, using a valved RV-PA conduit may limit any detrimental effects of conduit regurgitation and improve function and survival.

In this issue of the Journal, the largest single-center experience with the use of a valved RV-PA conduit in the Norwood operation for HLHS is presented. ${ }^{4}$ Sandeep and colleagues $^{4}$ report their 15 -year surgical experience with 130 patients managed with a valved (100 patients) or nonvalved (30 patients) RV-PA conduit at the time of Norwood operation. Overall mortality (18\%) was admirable as well as remarkable for the lack of difference between the valved and nonvalved conduit groups. Right ventricular function and tricuspid valve dimension at the time of bidirectional cavopulmonary shunt were similar in the 2 groups, with about one half the patients having conduit regurgitation. The rate of conduit intervention was greater in the valved group $(29 \%)$ versus the nonvalved group (15\%) but not statistically significant. This article is important in that despite

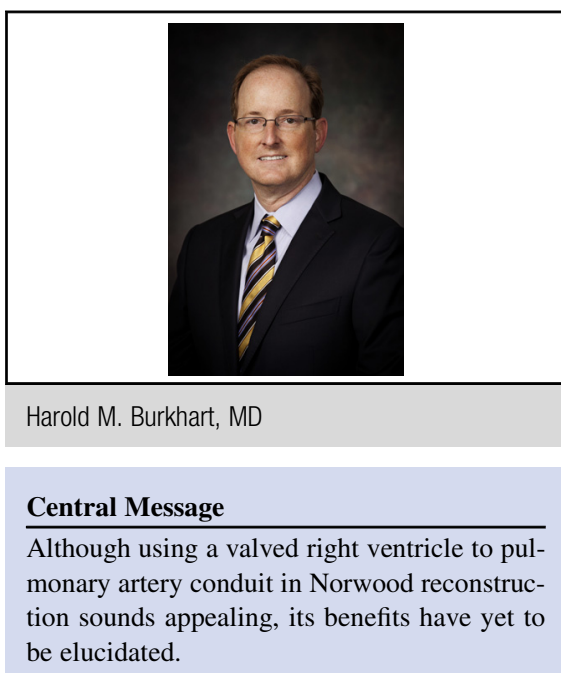

See Article page 1747.

the allure of placing a valved RV-PA conduit in the Norwood reconstruction, no appreciable benefit was demonstrated.

Although the manuscript provides important insight into the use of a valved RV-PA conduit in HLHS, there are limitations. Postoperatively, one would like to believe that the competent valve would confer better stability. Critical care data regarding ionotropic use may have supported this notion. Right ventricular size and function might be more accurately assessed with magnetic resonance imaging as opposed to echocardiography. ${ }^{5}$ A noticeable omission is the lack of branch pulmonary artery size data at the time of cardiac catheterization before bidirectional cavopulmonary shunt. Showing better pulmonary artery growth with a valved RV-PA conduit, as others have, would certainly enhance the argument for its use. Finally, the rate of intervention on the conduit is high in comparison with current techniques of nonvalved conduit implantation. ${ }^{7}$

The authors should be congratulated on their contributions to the search for the ideal pulmonary blood source for HLHS. Although they conclude the valved RV-PA conduit was not associated with improved survival or right ventricular function, there may be benefits that have yet to be elucidated. Further study and longer follow-up is warranted, specifically looking at postoperative stability, cardiac function, and pulmonary artery growth before discounting the appeal of the valved conduit. 


\section{References}

1. Sano S, Ishino K, Kawada M, Arai S, Kasahara S, Asai $T$, et al. Right ventricle-pulmonary artery shunt in first-stage palliation of hypoplastic left heart syndrome. J Thorac Cardiovasc Surg. 2003;126:504-9; discussion 509-10.

2. Wilder TJ, McCrindle BW, Phillips AB, Blackstone EH, Rajeswaran J, Williams WG, et al. Survival and right ventricular performance for matched children after stage-1 norwood: modified Blalock-Taussig shunt versus rightventricle-to-pulmonary-artery conduit. J Thorac Cardiovasc Surg. 2015;150: 1440-50.

3. Sharma V, Deo SV, Huebner M, Dearani JA, Burkhart HM. In search of the ideal pulmonary blood source for the Norwood procedure: a meta-analysis and systematic review. Ann Thorac Surg. 2014;98:142-50.
4. Sandeep N, Punn R, Balasubramanian S, Smith S, Reinhartz O, Zhang Y, et al. Interstage evaluation of homograft-valved right ventricle to pulmonary artery conduits for palliation of hypoplastic left heart syndrome. J Thorac Cardiovasc Surg. 2018; 155:1747-55.

5. Ruotsalainen H, Bellsham-Revell H, Bell A, Pihkala J, Ojala T, Simpson J. Right ventricular systolic function in hypoplastic left heart syndrome: a comparison of velocity vector imaging and magnetic resonance imaging. Pediatr Cardiol. 2014;35:1253-8.

6. Briceno-Medina M, Kumar TKS, Sathanandam S, Boston U, Perez M, Allen J, et al. Femoral vein homograft as Sano shunt results in improved pulmonary artery growth after Norwood operation. Cardiol Young. 2018;28:118-25.

7. Mascio CE, Spray TL. Distal dunk right ventricle to pulmonary artery shunt in stage 1 palliation. AnnThorac Surg. 2015;100:2381-2. 